\title{
ARIA 2019 Care Pathways for Allergic Rhinitis in the Kuwait Health Care System
}

\author{
Mona Al-Ahmad ${ }^{a}$ b Jasmina Nurkic ${ }^{b} \quad$ Claus Bachert $^{c, d} \quad$ Oliver Pfaar $^{e}$ \\ Holger J. Schunemann ${ }^{f}$ Wienczyslawa Czarlewskig Anna Bedbrook ${ }^{\text {h }}$ \\ Jean Bosquet ${ }^{i, j, k, 1}$
}

${ }^{\mathrm{a} M i c r o b i o l o g y}$ Department, Faculty of Medicine, Kuwait University, Kuwait City, Kuwait; ${ }^{\mathrm{b}} \mathrm{Al}$-Rashed Allergy Center, Ministry of Health, Kuwait City, Kuwait; 'Upper Airways Research Laboratory and Department of Oto-RhinoLaryngology, Ghent University and Ghent University Hospital, Ghent, Belgium; 'Division of ENT Diseases, CLINTEC, Karolinska Institute, University of Stockholm, Stockholm, Sweden; 'Department of Otorhinolaryngology, Head and Neck Surgery, Section of Rhinology and Allergy, University Hospital Marburg, Philipps-Universität Marburg, Marburg, Germany; 'Division of Immunology and Allergy, Department of Health Research Methods, Evidence and Impact, McMaster University, Hamilton, ON, Canada; 9 Medical Consulting Czarlewski, Levallois, France; hMACVIA-France, Fondation partenariale FMC VIA-LR, Montpellier, France; 'Contre les Maladies Chroniques pour un Vieillissement Actif en France, Montpellier, France; jINSERM, Ageing and Chronic Diseases Epidemiological and Public Health, Paris, France; ${ }^{k}$ Centre Hospitalier Universitaire de Montpellier, Montpellier, France; 'University Hospital, Montpellier, France

\section{Significance of the Study}

- The inclusion of integrated care pathways (ICPs) and health app with integrated person-centered care represents the management strategy of the Allergic Rhinitis and Its Impact on Asthma (ARIA) Phase 4.

- ICP can improve pharmacotherapy and allergen immunotherapy.

- Special features of Kuwait's health care system include the organization of tertiary health care which provides management of allergic rhinitis for Kuwaiti citizens and expatriates.

- ARIA guidelines are being integrated into Kuwait's health care system.

\section{Keywords}

Allergic rhinitis · Integrated care pathways · Allergen immunotherapy

\begin{abstract}
A worldwide increase in prevalence of allergic diseases has led to adaptations in national and international health care systems. ARIA (Allergic Rhinitis and Its Impact on Asthma) initiative develops internationally applicable guidelines for allergic respiratory diseases. In collaboration with international initiatives, ARIA offers updates of real-life integrated
\end{abstract}

karger@karger.com www.karger.com/mpp

Karger $\stackrel{\text { ' }}{5}$

GOPEN ACCESS
(C) 2020 The Author(s)

Published by S. Karger AG, Basel

This is an Open Access article licensed under the Creative Commons Attribution-NonCommercial-4.0 International License (CC BY-NC) (http://www.karger.com/Services/OpenAccessLicense), applicable to the online version of the article only. Usage and distribution for commercial purposes requires written permission. care pathways (ICPs) for digitally assisted, integrated, and individualized treatment of allergic rhinitis (AR). This article presents certain aspects of the health care system in Kuwait with reference to the management of $A R$ and the objective of introducing ICPs and adopting the latest ARIA recommendations. Guidelines for ICPs include aspects of patients and health care providers and cover key areas of management of AR. This model of guidelines supports real-life health care better than traditional models. ARIA recommendations will be locally integrated in the health care system with the aim of improving both pharmacotherapy and allergy immunotherapy.

(C) 2020 The Author(s)

Published by S. Karger AG, Basel
Mona Al-Ahmad

Department of Microbiology

Faculty of Medicine, Kuwait University

PO Box 24923, Kuwait City 13110 (Kuwait)

mona.alahmad@ku.edu.kw 


\section{Introduction}

Upgrades on management strategies are needed to support the improvement of the health care system due to a rapid increase in the burden and cost of allergic diseases worldwide [1]. A meeting for chronic disease care organized by MASK (Mobile Airways Sentinel Network) [2] and POLLAR (Impact of Air Pollution on Asthma and Rhinitis, European Institute for Innovation and Technology Health) [3] was held in Paris, on December 3,2018 , in collaboration with professional and patient organizations in the field of allergy and airway diseases. Real-life integrated care pathways (ICPs) were recommended for digitally enabled, integrated, and individualized care for rhinitis and asthma multimorbidity embedding environmental exposure [2]. ICPs are structured multidisciplinary plans detailing key steps of patient care [4]. They promote the translation of recommendations into local protocols and their application to clinical practice [5]. AIRWAYS ICPs (Integrated care pathways for airway diseases) [6] were the first steps towards the development of ICPs for rhinitis and asthma multimorbidity [7]. The urgent need to develop next-generation AR guidelines for pharmacotherapy and ICPs for allergen immunotherapy (AIT) resulted in two publications following the Paris meeting $[8,9]$. The ICP guidelines cover key areas of the care of AR patients with views from both patients and health care providers. The recommendations should be adapted to local conditions and national health systems. This article presents an overview of AR management in Kuwait with suggested adaptations based on latest ARIA recommendations supported by the Ministry of Health $(\mathrm{MOH})$ in Kuwait, Kuwait Society of Allergy and Clinical Immunology (KSACI), and Kuwait Thoracic Society (KTS).

\section{AR in Kuwait}

\section{Prevalence and Burden}

The International Study of Asthma and Allergies in Childhood (ISAAC), conducted in 1995-1996 [10] and in 2001-2002 [11] in Kuwait, estimated the prevalence of allergic diseases among school children. These studies indicated that allergic diseases are common in Kuwait and are comparable to estimates from Westernized countries with an increase in the diagnosis of AR from 17.1 to $22.2 \%$ over a period of 8 years [12]. In a recent cross-sectional study in Kuwait that involved university students (young adults), a large proportion of participants $(37.7 \%)$ report-

2019 ARIA Care Pathways in Kuwait ed current symptoms of rhinitis with an estimated prevalence of $20.4 \%$ [13]. With regard to allergic multimorbidity, the coexistence of "asthma and rhinitis" was the most common allergic multimorbidity which is supported by the "one airway, one disease" notion [14]. This was followed by the coexistence of "rhinitis and eczema" and "asthma, rhinitis, and eczema" among adults. The most common risk factors for the development of allergic diseases and allergic multimorbidity were parental history of allergic disease followed by pet ownership [14]. A crosssectional study in 2018, conducted in a single center in Kuwait, showed that only $30 \%$ of patients considered active management of AR while $70 \%$ responded that they do not use any medication [15]. The SNAPSHOT program provides current data on AR burden in the adult general population of 5 Middle Eastern countries (Egypt, Turkey, Kuwait, Saudi Arabia, and the United Arab Emirates, the latter three grouped into a Gulf cluster) [16]. AR in general results in a negative impact on quality of life, quality of sleep, and daily activities [16].

\section{Specific Risk Factors}

Kuwait is a desert country where the prevailing high temperatures, low humidity, and scant vegetation suggest a low prevalence of allergy. On the contrary, Ezeamuzie et al. [17] reported that Bermuda grass, house dust mite (Dermatophagoides pteronyssinus), and Chenopodium album are the most prevalent sensitizing allergens. Polysensitization was found to be common, and atopy was highly prevalent among young adults in $\mathrm{Ku}-$ wait, with a higher prevalence rate among citizens compared to expatriates which suggests the involvement of genetic or local environmental factors [17]. Behbehani et al. [18] identified two seasonal pollen peaks in Kuwait: grass (Gramineae spp.) peaked from April to May and weeds (Chenopodiaceae spp. and Amaranthaceae spp.) from September to October. These pollens appear to be the dominant aeroallergens because they are commonly identified during allergy skin testing and pollen surveys [19]. House dust mite, cat, and cockroach allergens are found in public places (e.g., mosques, restaurants, nurseries, hospitals, cinemas, and schools) but do not reach levels that are typically associated with exacerbation of symptoms [20].

Rates of cat and dog ownership are low in Kuwait because of cultural habits; however, stray cats may pose a relevant risk for developing perennial $\mathrm{AR}$, and therefore evaluation of sensitization by skin prick test and possibly nasal provocation test should be considered [21]. Indoor and outdoor molds, predominantly Alternaria, Aspergil- 
lus, Cladosporium, and Penicillium, primarily occurring during November to January and July, have a greater impact on individuals with asthma, rather than those with AR alone [22].

\section{Management of AR in Kuwait's Health Care System}

Both the national and private sectors provide health/ medical care for both citizens and expatriates, with primary health care being provided by the public sector. The health care system is organized in three sectors:

1. Primary health care is provided by general practitioners (GPs); patients with AR symptoms are usually first assessed in local polyclinics by GPs and are then sent to a specialized allergy center for further assessment.

2. Secondary health care is provided by medical specialists. According to the national health policy, patients are referred by primary care professionals for secondary care. Referrals are open to both citizens and expatriates in Kuwait. Ear-nose-throat specialists are consulted at this level for further assessment of AR patients.

3. Tertiary health care is usually specialized for inpatients, as well as for referrals from primary and secondary health care. More detailed investigations are usually carried out for targeted therapy. The tertiary allergy center is a public specialized center that provides full diagnostic and therapeutic options for patients. Recently, many institutions including the Ministry of Health (MOH), Kuwait Institute for Medical Specialization (KIMS), Kuwait University (KU), and Kuwait Foundation for the Advancement of Sciences (KFAS) have introduced a national allergy and clinical immunology training program in order to increase the number of allergists in Kuwait. More epidemiological studies are ongoing to ascertain the extent of burden of allergic diseases. Undergraduate and postgraduate trainees, as well as GPs, are receiving regular training in specialized tertiary centers, such as the Al-Rashed Allergy Center.

\section{ARIA Activities in Kuwait}

Many activities based on ARIA recommendations are regularly carried out under the supervision of the Ministry of Health. Continuous medical education by specialists in allergy and clinical immunology is provided for GPs and specialists. Guidelines for the management of $\mathrm{AR}$ and asthma are regularly updated and presented to health care practitioners. Pocket guides and treatment algorithms for physicians are distributed by the Kuwait So- ciety of Allergy and Clinical Immunology (KSACI). The tertiary allergy center has an important role in promotion of health care and generation of real-life data to facilitate the provision of all necessary resources for the establishment of ICPs in Kuwait. KSACI have used the tertiary center as a platform for health care promotion and education, with weekly case discussions, continuous medical education, and local and international meetings for all specialists. Furthermore, research studies and real-life data projects are conducted and published in peer-reviewed journals, under the support of the $\mathrm{MOH}$. Campaigns for public awareness of AR are organized on an annual basis, promoting the importance of early diagnosis, triggering factors, self-care, and updates on treatment. Such campaigns include the World Allergy Week, national AR patient advocacy group, and AR Annual Day.

\section{Next-Generation ARIA-GRADE Guidelines}

The GRADE (Grading of Recommendations, Assessment, Development, and Evaluation) methodology explicitly considers all types of study designs, but guideline developers often prefer to restrict guidelines to randomized control trials (RCTs). GRADE also considers evidence on values and preferences, acceptability and feasibility, or directness of findings. In order to implement the updated ARIA-GRADE guidelines on management of AR in Kuwait, we need to evaluate the local existing resources and ongoing initiatives in the health care system.

\section{Evidence Considered for the Development of ARIA ICPs}

The MASK algorithm based on the visual analog scale (VAS) was devised [29] and digitalized [30] to propose step-up or step-down AR treatment (Fig. 1). Although few head-to-head comparisons of medications using RCTs are available $[31,32]$, the comparison of AR medications has been proposed by reviews [28] and guidelines [24-26, 29]. A Health Technology Assessment concluded that most AR medications had a similar effect [33]. However, this study used a method that was too stringent, and that did not enable differentiation between medications. The ARIA revision 2016 [25] and the US Practice Parameters 2017 [26] developed independently used the same methodological approach, GRADE. Interestingly, the same questions were analyzed. Two major outcomes, efficacy and speed of action, were considered in the treat- 
Fig. 1. a Step-up algorithm in untreated patients using the visual analog scale (VAS) (adolescents over 12 years and adults). The proposed algorithm considers the treatment steps and the patient's preference. VAS levels are in ratio. If ocular symptoms remain once treatment has been initiated, add intraocular treatment. b Step-up algorithm in treated patients using the VAS (adolescents over 12 years and adults). The proposed algorithm considers the treatment steps and the patient's preference. VAS levels are in ratio. If ocular symptoms are remaining, add intraocular treatment. AIT, allergen immunotherapy.

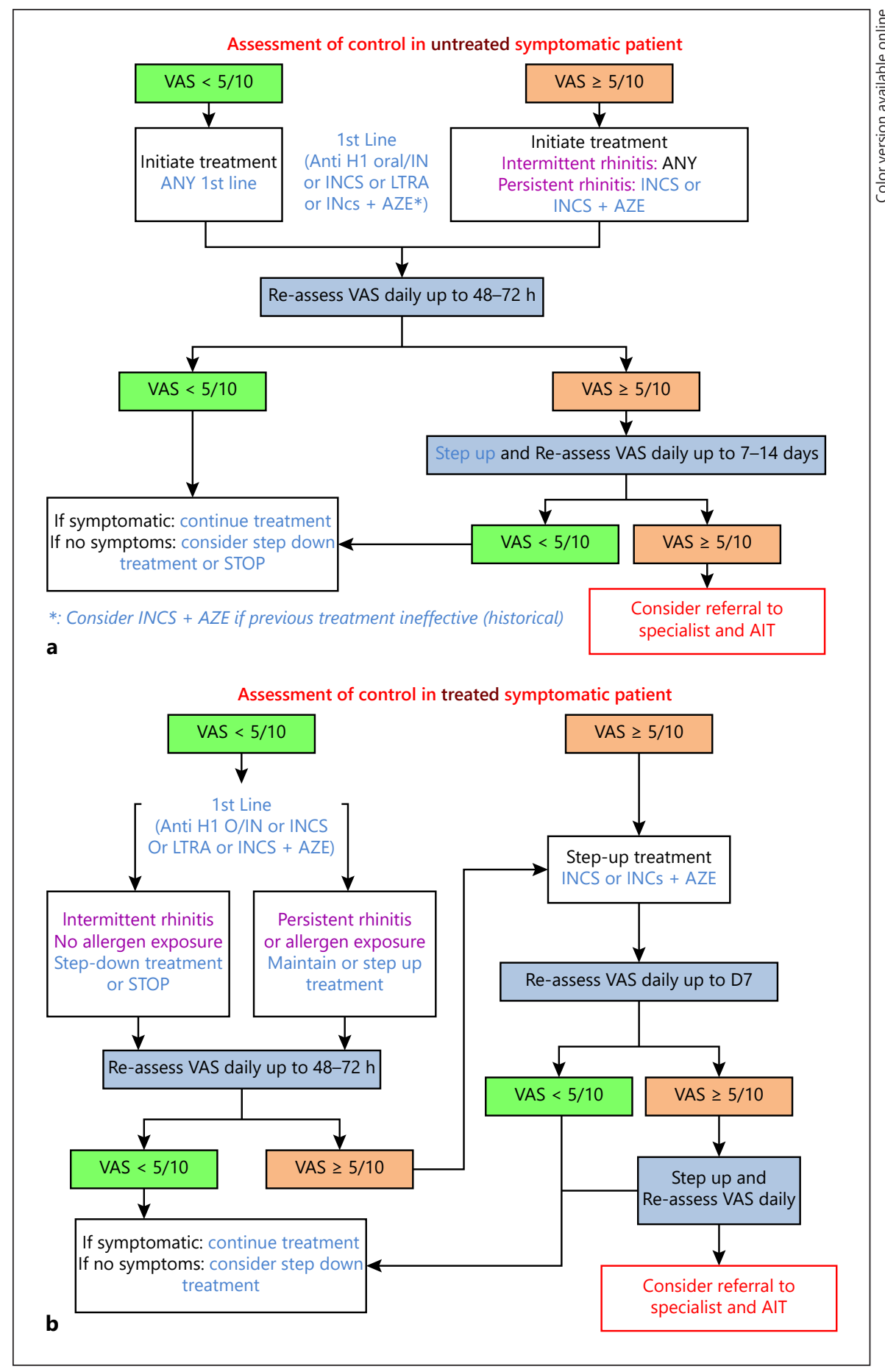

ment of moderate-severe rhinitis. For these recommendations, the level of evidence was low $[3,4]$ or very low [2]. The ARIA 2016 revision [25] and the US Practice Parameters 2017 [26], mainly based on RCTs, support the MASK algorithm [29].

\section{Pharmacological Treatment of AR}

Although the GRADE methodology considers all types of study designs, however, evidence on values, preferences, acceptability, and feasibility is equally important 
Table 1. Next-generation ARIA-GRADE guidelines

\begin{tabular}{|c|c|c|c|}
\hline Oral H1-antihistamines are less potent than INCSs but many patients prefer oral drugs & $\begin{array}{l}{[30]} \\
\text { No information on the } \\
\text { patient's preference }\end{array}$ & $\begin{array}{l}{[42,60]} \\
\text { No information on the } \\
\text { patient's preference }\end{array}$ & - \\
\hline Intranasal $\mathrm{H} 1$-antihistamines are less effective than INCSs & {$[28]$} & {$[33]$} & - \\
\hline INCSs are potent medications & {$[4,28]$} & {$[33]$} & - \\
\hline $\begin{array}{l}\text { The onset of action of INCSs takes a few hours to a few days (except for ciclesonide that is } \\
\text { effective quicker) }\end{array}$ & {$[28]$} & - & {$[41,50]$} \\
\hline The combination of INCSs and oral H1-antihistamines offers no advantage over INCSs & {$[3,4]$} & {$[33]$} & - \\
\hline Leukotriene antagonists are less potent than INCSs & {$[4,28]$} & - & - \\
\hline
\end{tabular}

for implementation of initiatives. There is an increasing trend to use real-world evidence (RWE) to inform clinical practice [23]. Ideally, both types of evidence should be merged. During the Paris meeting, next-generation guidelines for the pharmacologic treatment of AR were developed using existing GRADE-based guidelines for AR [24-26], tested using RWE and provided by mobile technology $[2,3,27]$ and chamber studies (Table 1). Although different types of studies (e.g., RCTs and park setting studies) were used for the evaluation of action of AR drugs, pollen exposure chambers of Ontario [34-37] and Vienna [38-40] proved to be more precise [38] and robust [39] than others. These recommendations were used to refine the MASK algorithm for treatment of AR proposed by a consensus group [29]. Overall, GRADE AR guidelines agree on certain important points [24-26, 31] (Box 1). Interestingly, all the components of the updated ARIA-based guidelines have been adopted in the treatment of AR patients in Kuwait. This recommendation, as shown in Box 1, is based on the availability of different modalities of pharmacotherapy and AIT that are made available by the $\mathrm{MOH}$ for treatment of AR. According to the local health care system, we are incorporating the updated MASK algorithm for treatment of AR in Kuwait.

\section{Box 1.}

Recommendations for pharmacotherapy in AR

Oral or intranasal $\mathrm{H1}$-antihistamines are less effective than intranasal corticosteroids (INCSs) for the control of all rhinitis symptoms [24, 44-46]. They are however effective in many patients with mild/moderate disease, and many patients prefer oral medications to intranasal ones. Comparisons between oral and intranasal H1-antihistamines differ between recommendations, and definite conclusions have not been reached. In patients with severe rhinitis, INCSs represent the first-line treatment. However, they need a few days to be fully effective.

The combination of an oral H1-antihistamine and an INCS does not offer a better efficacy than INCS alone $[25,26]$ although this practice is common globally. MPAzeFlu, combined intranasal fluticasone propionate and azelastine in a single device, is more effective than monotherapy and indicated when monotherapy with INCSs is considered inadequate [25, 26, 47, 48], for those with severe AR or for patients who want a rapid symptom relief $[25,26]$. A chamber study confirmed the speed of onset of the combination [34, 49]. All recommended medications are considered to be safe at the 
usual dosage. First-generation oral H1-antihistamines are sedating and should be avoided [51] as well as a prolonged use of nasal vasoconstrictors. Intramuscular depot corticosteroids are contraindicated for AR.

\section{RWE Using Mobile Technology}

Next-generation ARIA guidelines tested GRADE recommendations with RWE using data obtained by mHealth tools in order to confirm or refine them as well as the MASK algorithm. Although many mHealth tools are available for AR [40], only MASK has reported data on medications that can be used in RWE $[2,41]$. RWE indicated that patients did not follow guidelines, adherence to treatment was poor, often self-medicate depending on the control of the disease, and increase their treatment when they are unwell, comedication does not improve the control, and that MPAzeFlu is superior to INCSs which are superior to oral H1-antihistamines. Although adherence is impossible to be proved directly as MASK users do not report data every day and may not report all medications used, secondary adherence assessed using modified medication possession ratio and proportion of days covered was found to be $<5 \%$ [42]. As for all studies using participatory data, potential biases include the likelihood of sampling bias, outcome misclassification, and, due to ethical problems, availability of very little information on patient (or day) characteristics. App users are not representative of all patients with rhinitis. MASK used days in a cross-sectional analysis [2] because there is no clear pattern of treatment, and a longitudinal study was not feasible since users mostly use the app intermittently. AR diagnosis was not supported by a physician, but most users are likely to have AR or non-AR [2]. Precise patient characterization is impossible using an app due to privacy reasons. Although there are no data on the use of MASK in Kuwait, this is a promising initiative for implementation in Kuwait. Furthermore, mobile technology is becoming an important tool to better understand and manage AR and adds novel information that was not available with other methods $[2,43]$. To our knowledge, there is no other mHealth study to have assessed the efficacy of different medications at large scale.

\section{Disconnect between Patient and Physician's Perspectives}

There are differences between the physician's prescription and the patient's behavior for the treatment of pollen-induced AR. The vast majority of allergists pre-

2019 ARIA Care Pathways in Kuwait scribe medications for the entire season, recommending that the patient use them regularly, even on days with few symptoms. On the other hand, the vast majority of patients use their medications on demand when their AR is not well controlled and do not follow guidelines [2]. Unfortunately, this practice is also common in Kuwait. Although the health care system is fully supportive of management of AR for citizens and expatriates, poor compliance to given treatment is evident in daily practice. A possible explanation for this is the lack of a plan for management of AR based on a combination of physician's recommendations and patient's preferences which should be emphasized in educational activities for health care workers and patient groups as well. Hence, there is an obvious unmet need for implementing a new innovative management approach for AR patients, and the MASK project might indeed be a promising tool to address this issue.

\section{ARIA Care Pathways for AIT}

AIT is a proven therapeutic option for the treatment of $\mathrm{AR}$ and/or asthma by sublingual immunotherapy (SLIT) or subcutaneous immunotherapy (SCIT) routes $[24,50,52-54]$. The efficacy demonstrated in doubleblind, placebo-controlled, randomized clinical trials (DB-PC-RCT) was confirmed in studies using prescription databases and translates into real life [55]. In most countries, AIT is more expensive than other medical treatments for AR or asthma and should therefore be considered in patients within a selective medicine approach [56]. As recommended by the European Academy of Allergy and Clinical Immunology (EAACI) Task Force [57], ARIA 2019 has created ICPs for both SCIT and SLIT [58]. In Kuwait, AIT has to be introduced by allergy specialists in tertiary health care centers to patients with $\mathrm{AR}$ who are not controlled on standard treatment or referred from the primary and secondary health care systems due to the same issue. AIT is provided by the $\mathrm{MOH}$ for all patients.

The decision to prescribe AIT should be based on symptoms during allergen exposure, demonstration of sensitization, and availability of good-quality and standardized extracts, when possible [50]. AIT products have to show efficacy and safety in line with regulatory requirements [59]. Allergen extracts cannot be regarded as generics. There is no evidence that mixing different allergens has the same effect as separately administering individual allergens. Mixing can result in a dilutional effect and allergen 
degradation [60]. In many countries, named patient products are used to individualize the treatment to patients. However, this practice requires appropriate confirmatory trials and RWE. Patients are often sensitized to many allergens (polysensitization), but not all of these sensitizations may be clinically relevant. Therefore, it is important to use allergens inducing allergic symptoms and not sensitizations potentially irrelevant for the patient. Single extracts are effective in polysensitized patients [61]. In Kuwait, AIT has to be approved by the $\mathrm{MOH}$ according to a standard of adequate quality, efficacy, and safety profile. If imported from the European Union or USA, it has to be approved by the European Medical Agency (EMA) and the Food and Drug Administration (FDA). Allergens that are specific to Kuwait climate and environment are an ongoing project by the $\mathrm{MOH}$ and tertiary center in order to personalize treatment therapy. The safety profile of AIT is well established. SCIT typical local reaction is redness and swelling at the injection site immediately or several hours after the injection. Sometimes systemic reactions such as sneezing, nasal congestion, or hives can occur [62]. Serious reactions to subcutaneous injections are very rare but require immediate medical attention. Most reactions develop within $30 \mathrm{~min}$ after the injection, and it is therefore recommended that patients wait in their doctor's office for at least $30 \mathrm{~min}$ after an injection. On the other hand, SLIT in the form of drops or tablets has a more favorable safety profile than injections. SLIT can be administered at home after the first dose is administered under the supervision of a physician. A large majority of adverse events are local (e.g., mouth itching, lip swelling, and nausea) and spontaneously subside after the first days of administration. The severity of local side effects is graded according to persistence and impact on quality of life [63]. In Kuwait, SCIT is given in specialized allergy centers, and SLIT is prescribed for use in the patient's home with full instructions regarding possible mild to moderate side effects and ways to handle them. Patients are advised to follow-up regularly with the treating physician.

\section{Different Perspectives in Chain of AIT Application}

The shared decision-making (SDM) approach toward AIT, which is already known as specific [64] and challenging [65], is useful to make overviews of perspectives in the chain of AIT application. There are three different perspectives that are involved for the best SDM approach toward AIT.

\section{The Patient's Perspective}

The patient's perspective should always be considered to enable SDM. There are contrasting real-life studies assessing the level of knowledge, perceptions, expectations, and satisfaction of AIT $[66,67]$. However, a lack of information is common, and communication with allergic patients should be improved [68]. Adherence to AIT is crucial for its efficacy. Nonadherence to an AIT schedule and premature discontinuation are common [69]. Data on the rate of adherence to AIT are controversial, but it may be low [70]. A well-organized time schedule for allergists not only increases safety but also offers the possibility of close follow-up and an increase in patient adherence [69]. SDM should be applied from a medico-legal standpoint using current medical knowledge. Furthermore, the physician has the obligation to inform the patient about treatment options, risks, and benefits according to professional standards [71]. Patient's perspectives are taken into consideration when applying the SDM approach for AIT prescription in Kuwait. However, unfortunately, AR patients report noncompliance to AIT therapy, SLIT in particular, in the last few years [72]. Although patients get information about all available forms of AIT, physicians need to spend more time with patients to describe all aspects of therapy to improve compliance and secure close followup.

\section{Pharmacist's Views}

AIT products are available in the pharmacies of many countries, and in which case the pharmacist must be well informed about this treatment. Pharmacists may play an important role in educating patients about adherence and commitments involved in AIT as well as its risk benefits [73]. In Kuwait, AIT is available only in specialized tertiary centers and fully managed by specialists. This approach enables precise recruitment of eligible patients for therapy and accurate follow-up of patients.

\section{GP's Views}

Continuous and easily accessible primary care is vital in the management of $\mathrm{AR}$ and patient-centered SDM [74]. However, few GPs receive any formal undergraduate or postgraduate training in allergy [75]. Side effects of SCIT performed in primary care could be associated with some risks which can be minimized when given by trained GPs who carefully select patients in an appropriate environment with available primary care facilities for treating systemic anaphylactic reactions [76]. The $\mathrm{MOH}$ supports continuous medical education of GPs in all aspects and also emphasizes secondary and tertiary health care for 
more advanced diagnostic and treatment approaches. AIT must be prescribed by a specialist, with proper training in allergy, and following the SDM approach in $\mathrm{Ku}$ wait. Furthermore, although this therapy is expensive, the $\mathrm{MOH}$ covers fully or partially the cost of AIT depending on the type of health insurance.

\section{Selection of Allergic Patients for AIT}

The decision to prescribe an AIT should be based on the symptoms of allergen exposure, evidence of sensitization, clinical relevance, and availability of high-quality therapeutic extracts $[77,78]$. In some instances, AIT can be offered to patients whose AR is controlled by pharmacotherapy such as those who may develop thunderstorm-induced asthma [79]. AIT should also be considered even in moderate AR particularly, but not necessarily only, in patients who have asthma exacerbations during the pollen season and live in geographically at-risk regions. AIT should not be considered for severe and/or uncontrolled asthma patients [80]. An algorithm is not yet available for asthma. Uncontrolled asthma is still contraindicated for AIT [78]. The Global Initiative for Asthma (GINA) has endorsed SLIT for house dust mite-asthma [81]. The summary of product characteristics for the approved SLIT house dust mite tablet [82] states that (i) the patient should not have had a severe asthma exacerbation within the last 3 months of AIT initiation, (ii) initiation of treatment should be postponed until the infection has resolved in patients with asthma and experiencing an acute respiratory tract infection, (iii) AIT is not indicated for the treatment of acute exacerbations, and patients must be informed of the need to seek medical attention immediately if their asthma deteriorates suddenly, and (iv) mite AIT should initially be used as an add-on therapy to controller treatment, and reduction in asthma controllers should be performed gradually under the supervision of a physician according to management guidelines. No other AIT product has been approved in Europe as a primary indication for asthma. AR multimorbidity increases the severity of asthma [83]. AIT can control AR, conjunctivitis, and asthma multimorbidity. Multimorbidity was recognized as an indication for mite SLIT [82]. AIT is effective in children [84] and may have a long-term effect after it is stopped [85]. A recent study of SLIT [86], a previous study of grass pollen SCIT [87], and a meta-analysis [88] have all provided some evidence that AIT may de- lay or prevent the onset of asthma in children with rhinitis. However, the meta-analysis [88] showed a limited reduced short-term risk of developing asthma with unclear benefit over the longer term. Thus, AIT can be initiated in children with moderate/severe AR that is not controlled by pharmacotherapy. In such children without asthma, the possibility of preventing the onset of asthma should be taken into consideration, although more studies are needed for an unreserved indication [89]. The immunologic and allergic characteristics of older allergic patients differ from those of middle-aged adults. Limited studies suggested that AIT may be effective in older population [90]. More data are required for a universal recommendation; until further data are obtained, AIT is contraindicated in severe asthma in $\mathrm{Ku}$ wait, even if the patient has severe AR as a comorbidity.

\section{mHealth in the AIT Precision Medicine Approach}

Patient selection can be facilitated using electronic diaries obtained by cell phones $[27,91]$ or other mHealth tools. After a single year of survey, physicians can assess (i) whether moderate-severe uncontrolled disease is present, (ii) whether symptoms are associated with the pollen season or other allergen exposure, (iii) whether adherence to pharmacologic treatment is achieved, (iv) the duration of uncontrolled symptoms, and (v) the impact on productivity at school or at work. In the future, an electronic clinical decision support system may help the selection of patients for AIT [30]. The same approach can be proposed for the follow-up of patients on AIT to assess its efficacy [57]. Although mHealth is a promising technology that may help both patients and physicians, there is no mHealth tool currently available for AR patients in Kuwait.

\section{Conclusions}

The ARIA algorithm for AR was tested with RCTs, observational research RWE, and chamber studies in Kuwait. The overall algorithm was found to be appropriate, and no changes were needed. Comprehensive ICP guidelines can reflect real-life care better than traditional guidelines. GRADE recommendations are being integrated in the management of AR in Kuwait while mHealth applications are part of future challenges in patient care. Local tertiary health care facilities provide the optimum management plan for AR patients according to updated ARIA 
guidelines. AIT is an effective treatment for allergic diseases caused by inhaled allergens. It is supported by ARIA as a promising therapy, and its availability in Kuwait in different forms, together with other therapeutic modalities, further supports the local adaptation of GRADEARIA guidelines.

\section{Conflict of Interest Statement}

The authors have no conflict of interest to declare.

\section{References}

1 Bousquet J, Hellings PW, Agache I, Amat F, Annesi-Maesano I, Ansotegui IJ, et al. Allergic Rhinitis and its Impact on Asthma (ARIA) phase 4 (2018): change management in allergic rhinitis and asthma multimorbidity using mobile technology. J Allergy Clin Immunol. 2019;143(3):864-79.

2 Bousquet J, Arnavielhe S, Bedbrook A, Bewick M, Laune D, Mathieu-Dupas E, et al. MASK 2017: ARIA digitally-enabled, integrated, person-centred care for rhinitis and asthma multimorbidity using real-world-evidence. Clin Transl Allergy. 2018;8:45.

3 Bousquet J, Anto JM, Annesi-Maesano I, Dedeu T, Dupas E, Pépin JL, et al. POLLAR: impact of air POLLution on asthma and rhinitis; a European Institute of Innovation and Technology Health (EIT Health) project. Clin Transl Allergy. 2018;8:36.

4 Campbell H, Hotchkiss R, Bradshaw N, Porteous M. Integrated care pathways. BMJ. 1998;316(7125):133-7.

5 Palmer K, Marengoni A, Forjaz MJ, Jureviciene E, Laatikainen T, Mammarella F, et al. Multimorbidity care model: recommendations from the consensus meeting of the Joint Action on Chronic Diseases and Promoting Healthy Ageing across the Life Cycle (JA-CHRODIS). Health Policy. 2018;122(1):4-11.

6 Bousquet J, Addis A, Adcock I, Bousquet J, Addis A, Adcock I, et al. Integrated care pathways for airway diseases (AIRWAYS-ICPs). Eur Respir J. 2014;44(2):304-23.

7 Bousquet J, Onorato GL, Bachert C, Barbolini M, Bedbrook A, Bjermer L, et al. CHRODIS criteria applied to the MASK (MACVIAARIA Sentinel NetworK) good practice in allergic rhinitis: a SUNFRAIL report. Clin Transl Allergy. 2017;7:37.

8 Bousquet J, Pham-Thi N, Bedbrook A, Agache I, Annesi-Maesano I, Ansotegui A, et al. Next-generation care pathways for allergic rhinitis and asthma multimorbidity: a model for multimorbid non-communicable diseases. POLLAR (Impact of Air POLLution on asthma and rhinitis, member of EIT Health), GARD Research Demonstration Project, Reference Site Network of the European Innovation Partnership on Active and Healthy Ageing in revision. Clin Transl Allergy. 2019;9:44.

9 Bousquet J, Pham-Thi N, Bedbrook A, Agache I, Annesi-Maesano I, Ansotegui I, et al. Next-generation care pathways for allergic rhinitis and asthma multimorbidity: a model for multimorbid non-communicable diseases. PART 2: workshop report. POLLAR (Impact of Air POLLution on asthma and rhinitis, member of EIT Health), GARD Research Demonstration Project. Reference Site Network of the European Innovation Partnership on Active and Healthy Ageing in revision. 2018.

10 Behbehani NA, Abal A, Syabbalo N, Azeem AA, Shareef E, Al-Momen J. Prevalence of asthma, allergic rhinitis, and eczema in 13- to 14-year-old children in Kuwait: an ISAAC study. Ann Allergy Asthma Immunol. 2000; 85(1):58-63.

11 Owayed A, Behbehani N, Al-Momen J. Changing prevalence of asthma and allergic diseases among Kuwaiti children: an ISAAC study (phase III). Med Princ Pract. 2008; 17(4):284-9.

12 Mallol J, Crane J, von Mutius E, Odhiambo J, Keil U, Stewart A. The International Study of Asthma and Allergies in Childhood (ISAAC) phase three: a global synthesis. Allergol Immunopathol. 2013;41(2):73-85.

13 Ziyab AH. Prevalence and risk factors of asthma, rhinitis, and eczema and their multimorbidity among young adults in Kuwait: a crosssectional study. Biomed Res Int. 2017;2017: 2184193.

14 Leynaert B, Neukirch F, Demoly P, Bousquet J. Epidemiologic evidence for asthma and rhinitis comorbidity. J Allergy Clin Immunol. 2000;106(5 Suppl):S201-5.

15 Alkhaldy F, Abdelhamy A, Alsaeedi A. Cross sectional study: prevalence of allergic rhinitis among adult asthmatic patients in Kuwait. Arch Gen Intern Med. 2018;2(3).

16 Al-Digheari A, Mahboub B, Tarraf H, Yucel T, Annesi-Maesano I, Doble A, et al. The clinical burden of allergic rhinitis in five Middle Eastern countries: results of the SNAPSHOT program. Allergy Asthma Clin Immunol. 2018;14(1):63.

17 Ezeamuzie CI, Thomson MS, Al-Ali S, Dowaisan A, Khan M, Hijazi Z. Asthma in the desert: spectrum of the sensitizing aeroallergens. Allergy. 2000;55(2):157-62.

18 Behbehani N, Arifhodzic N, Al-Mousawi M, Marafie S, Ashkanani L, Moussa M, et al. The seasonal variation in allergic rhinitis and its correlation with outdoor allergens in Kuwait. Int Arch Allergy Immunol. 2004;133(2):1647.
19 Al-Dowaisan A, Fakim N, Khan MR, Arifhodzic N, Panicker R, Hanoon A, et al. Salsola pollen as a predominant cause of respiratory allergies in Kuwait. Ann Allergy Asthma Immunol. 2004;92(2):262-7.

20 Khan ZU, Khan MA, Chandy R, Sharma PN. Aspergillus and other moulds in the air of $\mathrm{Ku}$ wait. Mycopathologia. 1999;146(1):25-32.

21 Al-Ahmad M, Arifhodzic N, Nurkic J, Jusufovic $\mathrm{E}$, Hanoun $\mathrm{AL}$, Rodrigues T. Role of nasal challenge and local eosinophilia in indirect exposure to cat in allergic rhinitis patients. Eur Ann Allergy Clin Immunol. 2018;50(3): 125-31.

22 Al-Ahmad M, Jusufovic E, Arifhodzic N, Rodriguez T, Nurkic J. Association of molds and metrological parameters to frequency of severe asthma exacerbation. Allergy Asthma Clin Immunol. 2019;15(1):1-9.

23 Sherman RE, Anderson SA, Dal Pan GJ, Gray GW, Gross T, Hunter NL, et al. Real-world evidence: What is it and what can it tell us? $\mathrm{N}$ Engl J Med. 2016;375(23):2293-7.

24 Brozek JL, Bousquet J, Baena-Cagnani CE, Bonini S, Canonica GW, Casale TB, et al. Allergic Rhinitis and its Impact on Asthma (ARIA) guidelines: 2010 revision. J Allergy Clin Immunol. 2010;126(3):466-76.

25 Brozek JL, Bousquet J, Agache I, Agarwal A, Bachert C, Bosnic-Anticevich S, et al. Allergic Rhinitis and its Impact on Asthma (ARIA) guidelines: 2016 revision. J Allergy Clin Immunol. 2017;140(4):950-8.

26 Dykewicz MS, Wallace DV, Baroody F, Bernstein J, Craig T, Finegold I, et al. Treatment of seasonal allergic rhinitis: an evidence-based focused 2017 guideline update. Ann Allergy Asthma Immunol. 2017;119(6):489-511.e41.

27 Bousquet J, Devillier P, Arnavielhe S, Bedbrook A, Alexis-Alexandre G, van Eerd M, et al. Treatment of allergic rhinitis using mobile technology with real-world data: the MASK observational pilot study. Allergy. 2018;73(9): 1763-74.

28 Hujala A, Taskinen H, Richardson E, van Ginneken E. How to support integration to promote care for people with multimorbidity in Europe? Copenhagen: European Observatory Policy Briefs; 2017.

29 Bousquet J, Schünemann HJ, Hellings PW, Arnavielhe S, Bachert C, Bedbrook A, et al. MACVIA clinical decision algorithm in adolescents and adults with allergic rhinitis. J Allergy Clin Immunol. 2016;138(2):367-74.e2. 
30 Courbis AL, Murray RB, Arnavielhe S, Caimmi D, Bedbrook A, Van Eerd M, et al. Electronic Clinical Decision Support System for allergic rhinitis management: MASK e-CDSS. Clin Exp Allergy. 2018;48(12):1640-53.

31 Horak F, Bruttmann G, Pedrali P, Weeke B, Frølund L, Wolff HH, et al. A multicentric study of loratadine, terfenadine and placebo in patients with seasonal allergic rhinitis. Arzneimittelforschung. 1988;38(1):124-8.

32 Kaszuba SM, Baroody FM, deTineo M, Haney L, Blair C, Naclerio RM. Superiority of an intranasal corticosteroid compared with an oral antihistamine in the as-needed treatment of seasonal allergic rhinitis. Arch Intern Med. 2001;161(21):2581-7.

33 Glacy J, Putnam K, Godfrey S, Falzon L, Mauger B, Samson D, et al. Treatments for seasonal allergic rhinitis. In: AHRQ comparative effectiveness reviews. Rockville, MD: Agency for Healthcare Research and Quality; 2013.

34 Bousquet J, Meltzer EO, Couroux P, Koltun A, Kopietz F, Munzel U, et al. Onset of action of the fixed combination intranasal azelastine-fluticasone propionate in an allergen exposure chamber. J Allergy Clin Immunol Pract. 2018 Sep-Oct;6(5):1726-32.e6.

35 Patel P, Roland PS, Marple BF, Benninger PJ, Margalias H, Brubaker M, et al. An assessment of the onset and duration of action of olopatadine nasal spray. Otolaryngol Head Neck Surg. 2007;137(6):918-24.

36 Patel P, D'Andrea C, Sacks HJ. Onset of action of azelastine nasal spray compared with mometasone nasal spray and placebo in subjects with seasonal allergic rhinitis evaluated in an environmental exposure chamber. Am J Rhinol. 2007;21(4):499-503.

37 Salapatek AM, Lee J, Patel D, D'Angelo P, Liu J, Zimmerer RO Jr, et al. Solubilized nasal steroid (CDX-947) when combined in the same solution nasal spray with an antihistamine (CDX-313) provides improved, fast-acting symptom relief in patients with allergic rhinitis. Allergy Asthma Proc. 2011;32(3):221-9.

38 Horak F, Zieglmayer UP, Zieglmayer R, Kavina A, Marschall K, Munzel U, et al. Azelastine nasal spray and desloratadine tablets in pollen-induced seasonal allergic rhinitis: a pharmacodynamic study of onset of action and efficacy. Curr Med Res Opin. 2006;22(1): 151-7.

39 Murdoch RD, Bareille P, Ignar D, Miller SR, Gupta A, Boardley R, et al. The improved efficacy of a fixed-dose combination of fluticasone furoate and levocabastine relative to the individual components in the treatment of allergic rhinitis. Clin Exp Allergy. 2015;45(8): 1346-55.

40 Sleurs K, Seys SF, Bousquet J, Fokkens WJ, Gorris S, Pugin B, et al. Mobile health tools for the management of chronic respiratory diseases. Allergy. 2019;74(7):1292-306.

41 Bousquet J, Hellings PW, Agache I, Bedbrook A, Bachert C, Bergmann KC, et al. ARIA 2016: care pathways implementing emerging tech- nologies for predictive medicine in rhinitis and asthma across the life cycle. Clin Transl Allergy. 2016;6:47.

42 Menditto E, Guerriero F, Orlando V, Crola C Di Somma C, Illario M, et al. Self-assessment of adherence to medication: a case study in Campania region community-dwelling population. J Aging Res. 2015;2015:682503.

43 Bonini M. Electronic health (e-health): emerging role in asthma. Curr Opin Pulm Med. 2017;23(1):21-6.

44 Wallace DV, Dykewicz MS, Bernstein DI, Blessing-Moore J, Cox L, Khan DA, et al. The diagnosis and management of rhinitis: an updated practice parameter. J Allergy Clin Immunol. 2008;122(2 Suppl):S1-84.

45 Roberts G, Xatzipsalti M, Borrego LM, Custovic A, Halken S, Hellings PW, et al. Paediatric rhinitis: position paper of the European Academy of Allergy and Clinical Immunology. Allergy. 2013;68(9):1102-16.

46 Scadding GK, Kariyawasam HH, Scadding G, Mirakian R, Buckley RJ, Dixon T, et al. BSACI guideline for the diagnosis and management of allergic and non-allergic rhinitis (Revised Edition 2017; First edition 2007). Clin Exp Allergy. 2017;47(7):856-89.

47 Meltzer EO. Pharmacotherapeutic strategies for allergic rhinitis: matching treatment to symptoms, disease progression, and associated conditions. Allergy Asthma Proc. 2013; 34(4):301-11.

48 Seidman MD, Gurgel RK, Lin SY, Schwartz SR, Baroody FM, Bonner JR, et al. Clinical practice guideline: allergic rhinitis. Otolaryngol Head Neck Surg. 2015;152(1 Suppl):S143.

49 Bachert C, Bousquet J, Hellings P. Rapid onset of action and reduced nasal hyperreactivity: new targets in allergic rhinitis management. Clin Transl Allergy. 2018;8:25.

50 Bonertz A, Roberts G, Slater JE, Bridgewater J, Rabin RL, Hoefnagel M, et al. Allergen manufacturing and quality aspects for allergen immunotherapy in Europe and the United States: an analysis from the EAACI AIT Guidelines Project. Allergy. 2018;73(4):81626.

51 Church MK, Maurer M, Simons FE, BindslevJensen C, van Cauwenberge P, Bousquet J, et al. Risk of first-generation $\mathrm{H}(1)$-antihistamines: a GA(2)LEN position paper. Allergy. 2010;65(4):459-66.

52 Roberts G, Pfaar O, Akdis CA, Ansotegui IJ, Durham SR, Gerth van Wijk R, et al. EAACI guidelines on allergen immunotherapy: allergic rhinoconjunctivitis. Allergy. 2018;73(4): 765-98.

53 Ryan D, Gerth van Wijk R, Angier E, Kristiansen $M$, Zaman $H$, Sheikh A, et al. Challenges in the implementation of the EAACI AIT guidelines: a situational analysis of current provision of allergen immunotherapy. Allergy. 2018;73(4):827-36.

54 Muraro A, Roberts G, Halken S, Agache I, Angier E, Fernandez-Rivas $M$, et al. EAACI guidelines on allergen immunotherapy: ex- ecutive statement. Allergy. 2018;73(4):73943.

55 Zielen S, Devillier P, Heinrich J, Richter H, Wahn U. Sublingual immunotherapy provides long-term relief in allergic rhinitis and reduces the risk of asthma: a retrospective, real-world database analysis. Allergy. 2018; 73(1):165-77.

56 Larenas-Linnemann DES, Antolín-Amérigo D, Parisi C, Nakonechna A, Luna-Pech JA, Wedi B, et al. National clinical practice guidelines for allergen immunotherapy: an international assessment applying AGREE-II. Allergy. 2018;73(3):664-72.

57 Pfaar O, Demoly P, Gerth van Wijk R, Bonini $\mathrm{S}$, Bousquet J, Canonica GW, et al. Recommendations for the standardization of clinical outcomes used in allergen immunotherapy trials for allergic rhinoconjunctivitis: an EAACI position paper. Allergy. 2014;69(7):854-67.

58 Bousquet J, Pfaar O, Togias A, Schünemann HJ, Ansotegui I, Papadopoulos NG, et al. 2019 ARIA care pathways for allergen immunotherapy. Allergy. 2019;74(11):2087-102.

59 Kowalski ML, Ansotegui I, Aberer W, Al-Ahmad M, Akdis M, Ballmer-Weber BK, et al. Risk and safety requirements for diagnostic and therapeutic procedures in allergology: World Allergy Organization Statement. World Allergy Organ J. 2016;9(1):33.

60 Wheatley L, Wood R, Nadeau K, Liu A, Zoratti E, Bacharier L, et al. Mind the gaps: clinical trial concepts to address unanswered questions in aeroallergen immunotherapy. An NIAID/AHRQ workshop. J Allergy Clin Immunol. 2019;143(5):1711-26.

61 Nelson H, Blaiss M, Nolte H, Würtz S $\varnothing$, Andersen JS, Durham SR. Efficacy and safety of the SQ-standardized grass allergy immunotherapy tablet in mono- and polysensitized subjects. Allergy. 2013;68(2):252-5.

62 Cox L, Larenas-Linnemann D, Lockey RF, Passalacqua G. Speaking the same language: the World Allergy Organization Subcutaneous Immunotherapy Systemic Reaction Grading System. J Allergy Clin Immunol. 2010;125(3):569-74, 574.e1-7.

63 Passalacqua G, Baena-Cagnani CE, Bousquet J, Canonica GW, Casale TB, Cox L, et al. Grading local side effects of sublingual immunotherapy for respiratory allergy: speaking the same language. J Allergy Clin Immunol. 2013;132(1):93-8.

64 Durham SR. The allergen specificity of allergen immunotherapy-doubt no more. Allergy. 2019;74(11):2054-6.

65 Bonertz A, Roberts GC, Hoefnagel M, Timon $\mathrm{M}$, Slater JE, Rabin RL, et al. Challenges in the implementation of EAACI guidelines on allergen immunotherapy: a global perspective on the regulation of allergen products. Allergy. 2018;73(1):64-76.

66 Baiardini I, Puggioni F, Menoni S, Boot JD, Diamant Z, Braido F, et al. Patient knowledge, perceptions, expectations and satisfaction on allergen-specific immunotherapy: a survey. Respir Med. 2013;107(3):361-7. 
67 Nam YH, Lee SK. Physician's recommendation and explanation is important in the initiation and maintenance of allergen immunotherapy. Patient Prefer Adherence. 2017;11: 381-7.

68 Chivato T, Álvarez-Calderón P, Panizo C, Abengozar R, Alías C, Al-Baech A, et al. Clinical management, expectations, and satisfaction of patients with moderate to severe allergic rhinoconjunctivitis treated with SQ-standardized grass-allergen tablet under routine clinical practice conditions in Spain. Clin Mol Allergy. 2017;15:1.

69 Pitsios C, Dietis N. Ways to increase adherence to allergen immunotherapy. Curr Med Res Opin. 2018;1-9.

70 Bender BG, Lockey RF. Solving the problem of nonadherence to immunotherapy. Immunol Allergy Clin North Am. 2016;36(1):20513.

71 Bachert C, Strachwitz-Helmstatt KGV. Zur Diskussion gestellt: Der Arzt und die Spezifische Immuntherapie im Spannungsfeld von Leitlinie, Wirtschaftlichkeit und Medizinrecht. Allergologie. 2016;39(8):381-8.

72 Musaa F, Al-Ahmada M, Arifhodzic N, AlHerzc W. Compliance with allergen immunotherapy and factors affecting compliance among patients with respiratory allergies. Hum Vaccin Immunother. 2017;13(3):5147.

73 Kuehl BL, Abdulnour S, O’Dell M, Kyle TK. Understanding the role of the healthcare professional in patient self-management of allergic rhinitis. SAGE Open Med. 2015;3: 2050312115595822

74 Hellings PW, Fokkens WJ, Bachert C, Akdis CA, Bieber T, Agache I, et al. Positioning the principles of precision medicine in care pathways for allergic rhinitis and chronic rhinosinusitis: a EUFOREA-ARIA-EPOS-AIRWAYS ICP statement. Allergy. 2017;72(9): 1297-305.
75 Shehata Y, Ross M, Sheikh A. Undergraduate allergy teaching in a UK medical school: comparison of the described and delivered curriculum. Prim Care Respir J. 2007;16(1):1621.

76 Alvarez-Cuesta E, Bousquet J, Canonica GW, Durham SR, Malling HJ, Valovirta E. Standards for practical allergen-specific immunotherapy. Allergy. 2006;61(Suppl 82):1-20.

77 Bachert C, Larché M, Bonini S, Canonica GW, Kündig T, Larenas-Linnemann D, et al. Allergen immunotherapy on the way to product-based evaluation-a WAO statement World Allergy Organ J. 2015;8(1):29.

78 Bonertz A, G, Slater JE, Bridgewater G, Rabin RL, Hoefnagal M, et al. Allergen manufacturing and quality aspects for allergen immunotherapy in Europe and the United States: an analysis from the EAACI AIT Guidelines Project. Allergy. 2018;73(4):816-26.

79 O'Hehir RE, Varese NP, Deckert K, Zubrinich CM, van Zelm MC, Rolland JM, et al. Epidemic thunderstorm asthma protection with fivegrass pollen tablet sublingual immunotherapy: a clinical trial. Am J Respir Crit Care Med. 2018;198(1):126-8.

80 Pitsios C, Demoly P, Bilò MB, Gerth van Wijk R, Pfaar O, Sturm GJ, et al. Clinical contraindications to allergen immunotherapy: an EAACI position paper. Allergy. 2015;70(8): 897-909.

81 Global Strategy for Asthma Management and Prevention (2018 update). 2018. Available from wms-GINA-2018-report-V13-002pdf.

82 Summary of product characteristics. Acarizax 12 SQ-HDM oral lyophilisate. European Medicine Agency. 2016. Available from: http://https://mrictsmrpeu/Human/Downloads/DE_H_1947_001_FinalSPCpdf.

83 Amaral R, Fonseca JA, Jacinto T, Pereira AM, Malinovschi A, Janson C, et al. Having concomitant asthma phenotypes is common and independently relates to poor lung function in NHANES 2007-2012. Clin Transl Allergy. 2018;8:13.
84 Masuyama K, Okamoto Y, Okamiya K, Azuma R, Fujinami T, Riis B, et al. Efficacy and safety of SQ house dust mite sublingual immunotherapy-tablet in Japanese children. Allergy. 2018;73(12):2352-63.

85 Penagos M, Eifan AO, Durham SR, Scadding GW. Duration of allergen immunotherapy for long-term efficacy in allergic rhinoconjunctivitis. Curr Treat Options Allergy. 2018; 5(3):275-90.

86 Valovirta E, Petersen TH, Piotrowska T, Laursen MK, Andersen JS, Sørensen HF, et al. Results from the 5-year SQ grass sublingual immunotherapy tablet asthma prevention (GAP) trial in children with grass pollen allergy. J Allergy Clin Immunol. 2018;141(2): 529-e13.

87 Moller C, Dreborg S, Ferdousi HA, Halken S, Host A, Jacobsen L, et al. Pollen immunotherapy reduces the development of asthma in children with seasonal rhinoconjunctivitis (the PAT-study). J Allergy Clin Immunol. 2002;109(2):251-6.

88 Kristiansen M, Dhami S, Netuveli G, Halken S, Muraro A, Roberts G, et al. Allergen immunotherapy for the prevention of allergy: a systematic review and meta-analysis. Pediatr $\mathrm{Al}-$ lergy Immunol. 2017;28(1):18-29.

89 Halken S, Larenas-Linnemann D, Roberts G, Calderón MA, Angier E, Pfaar O, et al. EAACI guidelines on allergen immunotherapy: prevention of allergy. Pediatr Allergy Immunol. 2017;28(8):728-45.

90 Bozek A, Kolodziejczyk K, Kozlowska R, Canonica GW. Evidence of the efficacy and safety of house dust mite subcutaneous immunotherapy in elderly allergic rhinitis patients: a randomized, double-blind placebo-controlled trial. Clin Transl Allergy. 2017;7:43.

91 Bousquet J, Arnavielhe S, Bedbrook A, Fonseca J, Morais Almeida M, Todo Bom A, et al. The Allergic Rhinitis and its Impact on Asthma (ARIA) score of allergic rhinitis using mobile technology correlates with quality of life: the MASK study. Allergy. 2018;73(2):505-10. 